\title{
Docetaxel/Triptorelin Regimen
}

National Cancer Institute

\section{Source}

National Cancer Institute. Docetaxel/Triptorelin Regimen. NCI Thesaurus. Code C160514.

A regimen consisting of docetaxel and triptorelin that can be used for the treatment of prostate cancer. 